\title{
Perbedaan Pelepasan Ion Nikel (Ni) dan Kromium (Cr) Kawat Ortodonti Stainless Steel pada Perendaman Pasta Gigi Ortodonti dan Non-Ortodonti
}

\author{
Loisaviny H. D. Wondal \\ P. S. Anindita \\ Elita Tambunan \\ Program Studi Pendidikan Dokter Gigi Fakultas Kedokteran \\ Universitas Sam Ratulangi Manado \\ Email: loisa.viny97@gmail.com
}

\begin{abstract}
Recently, orthodontic toothpaste with colostrum has been introduced which is different from non-orthodontic toothpaste. Albeit, orthodontic and non-orthodontic toothpastes contain citric acid and some kinds of sodium compounds that can initiate corrosion of stainless steel orthodontic archwire indicated by the release of nickel and chromium ions. This study was aimed to determine the difference in nickel and chromium ion releases from the stainless steel orthodontic archwires immersed in artificial saliva plus orthodontic toothpaste or nonorthodontic toothpaste. This was a true experimental study with a post-test only control group design. Samples were stainless steel orthodontic archwires immersed in artificial saliva plus orthodontic toothpaste or non-orthodontic toothpaste. Released nickel and chromium ions were analyzed with atomic absorption spectrometer (AAS). In both treatment groups (orthodontic and non-orthodontic pastes), the independent t-test showed that the $P$ value of released nickel ions was 0.572 and of released chromium ions was $0.059(P>0.05)$. Conclusion: There were no significant differences between the release of nickel and chromium ions of stainless steel orthodontic archwires immersed in artificial saliva plus orthodontic toothpaste and in artificial saliva plus non-orthodontic toothpaste.

Keywords: stainless steel orthodontic archwire, nickel and chromium ion, orthodontic and non-orthodontic toothpaste.
\end{abstract}

\begin{abstract}
Abstrak: Dewasa ini sudah tersedia pasta gigi ortodonti dengan kandungan colostrum yang membedakannya dengan pasta gigi non-ortodonti. Pasta gigi ortodonti dan non-ortodonti mengandung citric acid dan beberapa jenis senyawa sodium yang dapat memicu terjadinya korosi pada kawat ortodonti stainless steel yang ditandai dengan pelepasan ion nikel dan kromium. Penelitian ini bertujuan untuk mengetahui apakah terdapat perbedaan jumlah pelepasan ion nikel dan kromium kawat ortodonti stainless steel yang direndam dalam pasta gigi ortodonti dan non-ortodonti. Jenis penelitian ialah eksperimental murni dengan post-test only control group design. Sampel yang digunakan yaitu kawat ortodonti stainless steel yang direndam dalam saliva artifisial ditambahkan pasta gigi ortodonti atau yang non-ortodonti. Pelepasan ion nikel dan kromium dianalisis menggunakan Spektrometri Serapan Atom (SSA). Hasil uji t tidak berpasangan pada kelompok perlakuan baik larutan pasta gigi ortodonti maupun yang non-ortodonti menunjukkan pelepasan ion nikel dengan $P=0,572$ dan pelepasan ion kromium dengan $P=0,059(P>0,05)$. Simpulan: Tidak terdapat perbedaan bermakna pelepasan ion nikel dan kromium pada kawat ortodonti stainless steel yang direndam dalam saliva artifisial ditambahkan pasta gigi ortodonti dibandingkan pasta non ortodonti.
\end{abstract}

Kata kunci: kawat ortodonti stainless steel, nikel, kromium, pasta gigi ortodonti dan non ortodonti 
Piranti ortodonti cekat saat ini sudah banyak digunakan secara luas, baik orang dewasa maupun anak-anak, sebagai upaya untuk mendapatkan susunan gigi yang baik. ${ }^{1,2}$ Piranti ortodonti cekat merupakan piranti yang tidak dapat dilepas sendiri oleh pasien dan berada dalam rongga mulut dalam waktu yang lebih lama dibandingkan piranti ortodonti lepasan. Piranti ortodonti cekat memiliki komponen dasar berupa breket, kawat ortodonti atau kawat busur, dan auxiliaries. ${ }^{2}$ Kawat ortodonti yang digunakan pada tahap awal perawatan dengan piranti ortodonti cekat yaitu kawat busur, bentuk penampang bulat, dengan bahan stainless steel. ${ }^{2,3}$

Kawat ortodonti stainless steel dikenal sebagai baja tahan korosi yang mengandung $70 \%$ besi (Fe), 0,2\% karbon (C), 18\% kromium $(\mathrm{Cr})$ dan $8 \%$ nikel $(\mathrm{Ni}),{ }^{4}$ dan paling sering digunakan karena memiliki struktur dan sifat mekanik yang menguntungkan sebagai kawat busur pada piranti ortodonti cekat serta harga yang terjangkau. ${ }^{4,5}$ Walaupun murah dan terjangkau, interaksi dan kontak yang terus menerus dengan kondisi dalam rongga mulut terutama cairan fisiologik seperti saliva dapat memengaruhi keadaan material kawat ortodonti stainless steel, yaitu terjadinya proses korosi. ${ }^{4}$ Korosi ditandai dengan pelepasan ion logam dalam stainless steel terutama nikel dan kromium. ${ }^{6,7}$

Korosi dapat disebabkan oleh kandungan yang ada dalam saliva seperti air, oksigen, dan ion klorida, yang ditandai dengan adanya pelepasan ion logam. ${ }^{4}$ Selain itu, berbagai kandungan asam dan sodium dari obat kumur juga dapat memperberat terjadinya korosi kawat stainless steel. ${ }^{4,8}$ Hal ini didukung oleh penelitian yang dilakukan oleh Dundu et al. ${ }^{9}$ di Semarang yang menyatakanan bahwa larutan ekstrak daun sirih $50 \%$ sebagai bahan dalam obat kumur tidak efektif digunakan sebagai alternatif untuk menghambat pelepasan ion metal $(\mathrm{Ni}, \mathrm{Cr}$, dan $\mathrm{Fe})$. Penelitian lain yang dilakukan oleh Minanga $^{8}$ di Manado menunjukkan bahwa kandungan dalam obat kumur dapat memperberat korosi pada kawat ortodonti stainless steel, yaitu kandungan citric acid, benzoic acid, sodium fluoride, sodium citrate. Kandungan bahan-bahan tersebut dapat juga ditemukan dalam pasta gigi.

Pasta gigi merupakan sediaan semi padat yang digunakan untuk membantu membersihkan rongga mulut. Kebutuhan pasta gigi menjadi sangat penting bagi masyarakat berkaitan dengan kesehatan rongga mulut, termasuk bagi pengguna ortodonti cekat. ${ }^{10}$ Menurut Kementerian Kesehatan Republik Indonesia, penggunaan pasta gigi yang disarankan yaitu minimal 2 kali sehari bersama dengan sikat gigi. ${ }^{11}$ Kini pasta gigi hadir dengan bermacammacam fungsi dan rasa, baik pasta gigi untuk orang dewasa maupun anak-anak. Ada pasta gigi untuk memutihkan gigi, untuk mencegah bau mulut, untuk gigi sensitif, pasta gigi khusus perokok, dan pasta gigi khusus pengguna piranti ortodonti. $^{10}$

Setiap pasta gigi yang tersebar di pasaran tentunya memiliki kandungan yang berbeda, termasuk kandungan yang terdapat dalam pasta gigi ortodonti. Perbedaan kandungan pasta gigi ortodonti dengan non-ortodonti yaitu adanya kandungan colostrum pada pasta gigi ortodonti, namun kandungan lainnya sama dengan pasta gigi non-ortodonti. Kandungan dalam pasta gigi ortodonti maupun non-ortodonti yang terdapat juga dalam obat kumur membuat pasta gigi tersebut diduga dapat menyebabkan korosi pada kawat ortodonti stainless steel, namun belum diketahui perbedaan besar pengaruh pasta gigi ortodonti dan non-ortodonti terhadap terjadinya korosi, yang ditandai dengan pelepasan ion nikel dan kromium.

\section{METODE PENELITIAN}

Jenis penelitian ini yaitu eksperimental murni dengan post-test only control group design. Penelitian dilakukan di Laboratorium Farmasi Fakultas MIPA Universitas Sam Ratulangi untuk pembuatan saliva artifisial dan di Balai Teknis Kesehatan Lingkungan dan Pengendalian Penyakit (BTKL-PP) Kelas 1 Manado untuk analisis pelepasan ion nikel $(\mathrm{Ni})$ dan kromium $(\mathrm{Cr})$, 
pada bulan Mei 2018. Sampel penelitian ini yaitu 9 buah kawat ortodonti stainless steel dengan penampang berbentuk bulat berdiameter 0,016 inci untuk rahang atas, yang digunakan pada piranti ortodonti cekat. Pengukuran jumlah pelepasan ion $\mathrm{Ni}$ dan $\mathrm{Cr}$ pada sampel kontrol dan perlakuan menggunakan alat Spektrometri Serapan Atom (SSA).

Pelaksanaan penelitian diawali pembuatan saliva artifisial (saliva buatan) dengan $\mathrm{pH}$ 6,8 menggunakan metode Afnor. Volume saliva arfisial yang dibutuhkan untuk setiap perendaman yaitu $50 \mathrm{ml}$ dan berat pasta gigi yaitu $16,17 \mathrm{gr}$, kemudian dilakukan pencampuran saliva artifisial dengan pasta gigi ortodonti atau non-ortodonti. Perendaman kawat kelompok kontrol dalam saliva artifisial sebanyak 3 buah kawat. Kelompok perlakuan terdiri dari dua perlakuan yaitu 3 buah kawat dalam saliva artifisial ditambahkan pasta gigi ortodonti dan 3 buah kawat dalam saliva artifisial ditambahkan pasta gigi nonortodonti. Dilakukan pembuatan larutan blanko yaitu saliva artifisial ditambah pasta gigi ortodonti dan non-ortodonti tanpa dilakukan perendaman kawat. Perendaman dilakukan dalam gelas piala, ditutup dengan aluminium foil, dan dilakukan penyimpanan dalam inkubator pada suhu $37^{\circ} \mathrm{C}$ selama 720 menit.

Setelah perendaman dalam inkubator, kawat ortodonti stainless steel dipisahkan dari larutan perendaman dan dilanjutkan dengan analisis pelepasan ion $\mathrm{Ni}$ dan $\mathrm{Cr}$ menggunakan SSA. Data hasil penelitian diolah menggunakan uji statistik ShapiroWilk (uji normalitas) dan uji t tidak berpasangan (uji komparasi), kemudian disajikan dalam bentuk tabel.

\section{HASIL PENELITIAN}

Hasil penelitian menunjukkan bahwa rerata jumlah pelepasan ion $\mathrm{Ni}$ dan $\mathrm{Cr}$ pada kelompok perlakuan (pasta gigi ortodonti dan non-ortodonti) lebih besar daripada kelompok kontrol (saliva artifisial). Jumlah pelepasan ion $\mathrm{Cr}$ pada kelompok kontrol dan perlakuan lebih besar daripada jumlah pelepasan ion Ni. Rerata jumlah pelepasan ion
$\mathrm{Ni}$ dan $\mathrm{Cr}$ pada larutan pasta gigi ortodonti lebih kecil dibandingkan pada larutan pasta gigi non-ortodonti (Gambar 1).

Hasil uji normalitas Shapiro-Wilk menunjukkan bahwa data pengukuran pelepasan ion nikel dan kromium pada kelompok perlakuan terdistribusi normal $(P$ $>0,05)$, sehingga uji statistik dilanjutkan dengan uji t tidak berpasangan pada derajat signifikansi $P<0,05$ untuk melihat ada tidaknya perbedaan yang bermakna (Tabel 1).

Hasil uji $\mathrm{T}$ tidak berpasangan pada kelompok perlakuan baik larutan pasta gigi ortodonti maupun larutan pasta gigi nonortodonti menunjukkan nilai pelepasan ion nikel dengan signifikansi 0,572 $(P>0,05)$. Pelepasan ion kromium pada kelompok perlakuan baik larutan pasta gigi ortodonti maupuan larutan pasta gigi non-ortodonti menunjukkan nilai signifikansi 0,059 ( $P$ $>0,05)$. Berdasarkan hasil di atas maka dapat dinyatakan bahwa tidak terdapat perbedaan bermakna jumlah pelepasan ion nikel maupun ion kromium kawat ortodonti stainless steel yang direndam dalam larutan pasta gigi ortodonti dan larutan pasta gigi non-ortodonti.

\section{BAHASAN}

Hasil pengukuran pada kelompok perlakuan baik larutan pasta gigi ortodonti dan non-ortodonti menunjukkan pelepasan ion nikel dan kromium dengan rerata yang bervariasi untuk kedua larutan tersebut. Pengukuran ion nikel dan kromium juga dilakukan pada larutan blanko yaitu saliva artifisial ditambahkan pasta gigi ortodonti dan saliva artifisial ditambahkan pasta gigi ortodonti. Analisis dilakukan pada larutan blanko dengan tujuan untuk mengetahui ada tidaknya ion nikel dan kromium tanpa dilakukan perendaman kawat ortodonti stainless steel.

Pelepasan ion nikel dan kromium pada kelompok perlakuan baik larutan pasta gigi ortodonti maupun non-ortodonti lebih besar dibandingkan kelompok kontrol. Hal ini disebabkan oleh adanya penambahan pasta gigi pada saliva artificial yang mengakibatkan penurunan $\mathrm{pH}$ saliva. 


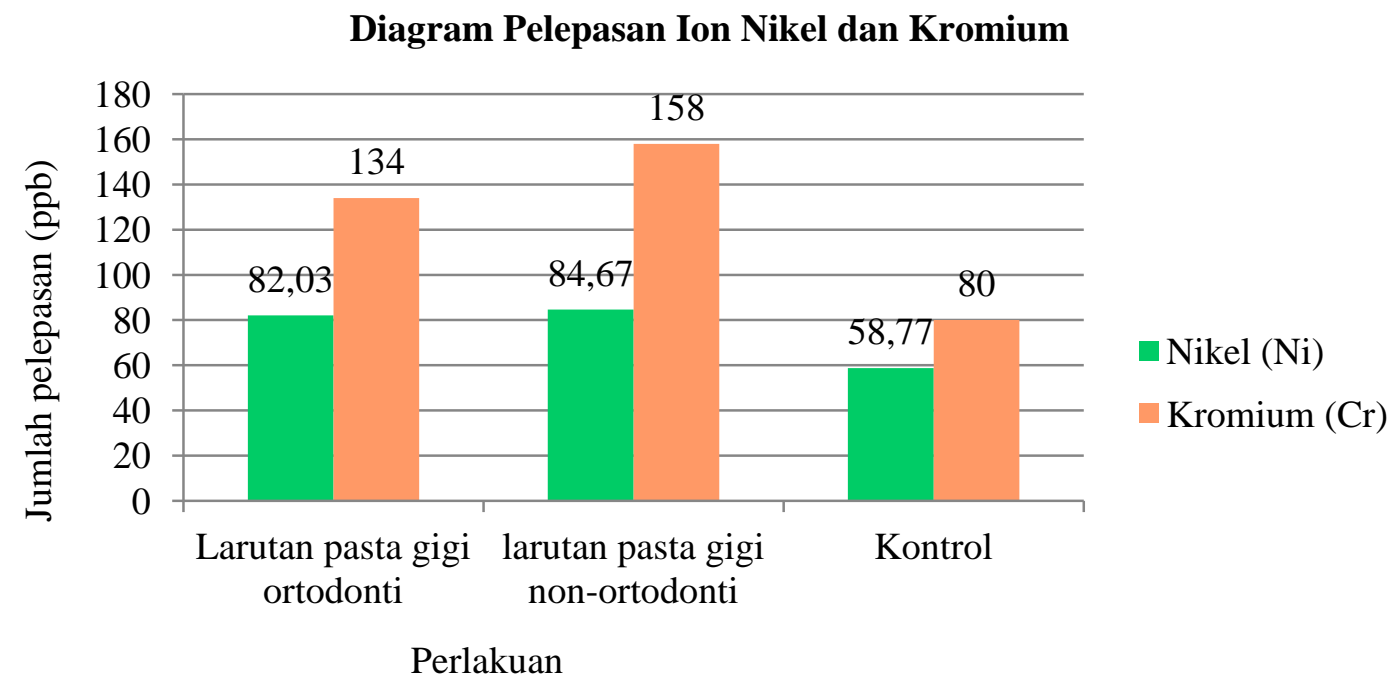

Gambar 1. Rerata jumlah pelepasan ion nikel dan kromium kawat ortodonti stainless steel

Tabel 1. Hasil uji T tidak berpasangan: pelepasan ion nikel dan kromium larutan pasta gigi ortodonti dan non-ortodonti

\begin{tabular}{cccc}
\hline Variabel pengukur & \multicolumn{2}{c}{ Perbandingan pelepasan ion } & P (probabilitas) \\
\hline Nikel $(\mathrm{Ni})$ & $\begin{array}{c}\text { Larutan pasta gigi } \\
\text { ortodonti }\end{array}$ & $\begin{array}{c}\text { Larutan pasta gigi } \\
\text { non-ortodonti }\end{array}$ & 0,572 \\
Kromium $(\mathrm{Cr})$ & 0,059 \\
\hline
\end{tabular}

Uji T tidak berpasangan; signifikansi $P<0,05$

Pasta gigi ortodonti dan non-ortodonti mengandung citric acid $\left(\mathrm{C}_{6} \mathrm{H}_{8} \mathrm{O}_{7}\right)$ dengan partikel $\mathrm{H}^{+}$yang cukup tinggi dan dapat meningkat jika bereaksi dengan logam, sehingga terjadi penurunan $\mathrm{pH}$ saliva yang memicu laju korosi menjadi lebih cepat, ditandai dengan pelepasan ion nikel dan kromium. ${ }^{12}$ Hal ini sejalan dengan penelitian yang dilakukan oleh Kristianingsih et al. ${ }^{13}$ di Jember mengenai pelepasan ion nikel dan kromium kawat ortodontik stainless steel pada perendaman minuman berkarbonasi. Hasil penelitian tersebut menunjukkan bahwa lebih besar pelepasan ion nikel dan kromium pada minuman berkarbonasi dengan $\mathrm{pH}$ rendah dibandingkan dalam saliva dengan $\mathrm{pH}$ netral.

Beberapa jenis sodium yang terkandung dalam pasta gigi ortodonti dan nonortodonti juga mendukung terjadinya pelepasan ion nikel dan kromium kawat ortodonti stainless steel, yaitu sodium benzoate, sodium fluoride, dan sodium saccharin. Kandungan tersebut merupakan garam yang akan membentuk larutan elektrolit, dan dapat memicu terjadi korosi pada kawat ortodonti stainless steel yang ditandai dengan pelepasan ion nikel dan kromium. Hal ini didukung dengan penelitian yang dilakukan oleh Minanga et al. ${ }^{8}$ mengenai pelepasan ion nikel dan kromium kawat ortodonti stainless steel yang direndam dalam obat kumur. Hal ini diperkuat dengan penelitian yang dilakukan oleh Schiff et al. ${ }^{14}$ di Prancis yang melaporkan bahwa pasien yang memakai breket ortodonti logam dengan komposisi dasar $\mathrm{Fe}$, $\mathrm{Cr}$, Ni atau Ti disaranakan tidak memakai obat kumur Meridol yang me-ngandung aqua, olaflur, aroma, stannous fluoride, dan sodium saccharin karena dapat menurunkan tingkat ketahanan korosi.

Hasil pengukuran pada kelompok perlakuan dan kelompok kontrol menun- 
jukkan rerata jumlah pelepasan ion nikel lebih kecil dibandingkan rerata jumlah pelepasan ion kromium. Hal ini sejalan dengan klasifikasi yang ditetapkan oleh American Iron Steel Institute (AISI) yaitu kandungan kromium harus lebih besar dibandingkan kandungan nikel yaitu kromium sebesar $18 \%$ dan nikel sebesar $8 \%{ }^{4,15} \mathrm{Hal}$ ini diperkuat dengan penelitian yang dilakukan oleh Bonde et al. ${ }^{16}$ di Manado yang menyatakan bahwa jumlah ion kromium lebih besar daripada jumlah ion nikel yang terlepas dari kawat ortodonti stainless steel. Pelepasan ion kromium yang lebih besar dibandingkan ion nikel disebabkan oleh unsur kromium yang memiliki nilai potensial elektroda lebih negatif dari nikel, karena posisi unsur kromium dalam deret Volta lebih ke kiri dari posisi unsur nikel. Hal ini menyebabkan unsur kromium lebih reaktif dan mudah melepas elektron, sehingga jumlah pelepasan ion kromium lebih besar dibandingkan ion nikel. ${ }^{4,5}$

Hasil pengukuran pada kelompok perlakuan menunjukkan jumlah pelepasan ion nikel dan kromium lebih kecil pada larutan pasta gigi ortodonti dibandingkan pada larutan pasta gigi non-ortodonti, namun tidak terdapat perbedaan bermakna antara kedua larutan tersebut. Faktor yang menyebabkan pelepasan ion nikel dan kromium pada larutan pasta gigi ortodonti lebih kecil dibandingkan larutan pasta gigi non-ortodonti yaitu larutan pasta gigi nonortodonti memiliki $\mathrm{pH}$ lebih rendah dibandingkan larutan pasta gigi ortodonti. Korosi elektrokimia tergantung pada komposisi larutan, konsentrasi komponennya, $\mathrm{pH}$ dan lain sebagainya. Faktor-faktor tersebut memengaruhi kekuatan setiap elektrolit dan besar proses korosi yang terjadi. Saliva artifisial mengandung bahan anorganik (bikarbonat, fosfat, natrium, kalium, klorida dan magnesium) dalam saliva dengan $\mathrm{pH}$ netral yang memicu reaksi elektrokimia. $^{17}$ Reaksi elektrokimia merupakan reaksi yang terjadi pada anoda (mengalami oksidasi) dan katoda (mengalami reduksi), ion logam berperan sebagai anoda dan ion $\mathrm{H}^{+}$dari media elektrolit sebagai katoda.
Adanya penambahan pasta gigi menyebabkan $\mathrm{pH}$ larutan semakin rendah, sehingga dapat mempercepat terjadinya reaksi elektrokimia. Reaksi elektrokimia ini menyebabkan kerusakan lapisan pelindung logam pada kawat ortodonti stainless steel berupa korosi yang ditandai dengan pelepasan ion nikel dan kromium. ${ }^{4}$

Pelepasan ion nikel dan kromium yang lebih kecil pada larutan pasta gigi ortodonti disebabkan oleh adanya kandungan colostrum yang berfungsi untuk melembabkan lingkungan rongga mulut sehingga $\mathrm{pH}$ pada larutan pasta gigi ortodonti lebih tinggi dibandingkan dengan $\mathrm{pH}$ larutan pasta gigi non-ortodonti. Hal ini sejalan dengan penelitian yang dilakukan oleh Laksmitaputri dan Prahastuti ${ }^{18}$ di Yoyakarta yang menunjukkan bahwa pasta gigi ortodonti dengan kandungan colostrum memilki $\mathrm{pH}$ yang lebih tinggi dibandingkan pasta gigi herbal (pasta gigi nonortodonti). Walaupun tidak berbeda secara bermakna, adanya variasi jumlah pelepasan ion nikel dan kromium pada pasta gigi ortodonti dan non-ortodonti dapat menjadi pertimbangan dalam pemilihan pasta gigi untuk digunakan selama perawatan dengan piranti ortodonti cekat, sehingga efek samping korosi terhadap tubuh seperti terpicunya reaksi alergi, efek karsinogenik, mutagenic, dan sito-toksik dapat dihindari. ${ }^{6}$

\section{SIMPULAN}

Dari hasil penelitian ini dapat disimpulklan bahwa tidak terdapat perbedaan bermakna jumlah pelepasan ion nikel dan kromium kawat ortodonti stainless steel yang direndam dalam saliva artifisial ditambahkan pasta gigi ortodonti dengan yang ditambahkan pasta gigi non-ortodonti.

\section{SARAN}

Disarankan untuk melakukan penelitian serupa dengan $\mathrm{pH}$ saliva artifisial yang lebih tinggi namun masih dalam batas normal $\mathrm{pH}$ saliva.

Disarankan untuk melakukan penelitian serupa namun menggunakan pasta gigi non-ortodonti yang mengandung deterjen sebagai pembanding. 
Disarankan bagi dokter gigi untuk menyarankan pasien menggunakan pasta gigi ortodonti selama penggunaan piranti ortodonti cekat, karena jumlah pelepasan ion nikel dan kromium lebih rendah dibandingkan menggunakan pasta gigi nonortodonti.

\section{DAFTAR PUSTAKA}

1. Mararu WP, Zuliari K, Mintjelungan CN. Gambaran status kebersihan gigi dan mulut pada pengguna alat ortodonti cekat di SMA Negeri 7 Manado. eG. 2017;5(2):159-65.

2. Rahardjo P. Ortodonti Dasar (2nd ed). Surabaya: Airlangga University Press, 2012; p. 128-37.

3. Bishara SE. Textbook of Orthodontics. Philadelphia: Saunders, 2001; p. 203-5.

4. Anusavice KJ. Phillips Buku Ajar Ilmu Bahan Kedokteran Gigi (10th ed). Budiman JA, Purwoko S, penerjemah. Jakarta: EGC, 1996; p. 290-8.

5. Avi L, Thahar B, Merdiati E. Pengaruh heat treatment untuk mengembalikan sifat mekanik kawat T-loop segmental stainless steel terhadap besaran gaya yang dihasilkan. MBK. 2015;47(3): 167-73.

6. Andersen A, Baker D, Beyersmann D, Costa M, de Flora S, Gilman JPW, et al. IARC monographs on the evaluation of carcinogenic risk to humans: chromium, nickel, and welding Volume 49. Lyon: WHO, 1990; 49: 407-9.

7. Sembel DT. Toksikologi Lingkungan. Yogyakarta: Penerbit Andi, 2015; p. 112.

8. Minanga MA, Anindita PS, Juliatri. Pelepasan ion nikel dan kromium breket ortodontik stainless steel yang direndam dalam obat kumur. Pharmacon. 2016;5(1):135-41.

9. Dundu MAJ, Aditya G, Hadianto E. Pengaruh larutan ekstrak daun sirih (Piper bitie L) $50 \%$ terhadap pelepasan ion metal (Ni, Cr dan $\mathrm{Fe}$ ) pada breket ortodontik. Odonto Dental Journal 2017;4(1):32-7.

10. Novia DRM. Etik kritis pasta gigi. Tabloid Republika Dialog Jumat 13 Agustus 2010. p 13. [cited 2018 Mar 20]. Available from: http://ftp.unpad.ac.id/ koran/republika/2010-08-13/republika _2010_08_13_163.pdf.

11. Kemenkes RI. Buku Panduan Pelatihan Kader Kesehatan Gigi dan Mulut di Masyarakat. Jakarta: Kementerian Kesehatan RI, 2012; p. 16.

12. Fontana MG. Corrosion Engineering (3rd ed). Singapore: Mc.Graw-Hill, 1987.

13. Kristianingsih R, Joelijanto R, Praharani D. Analisis pelepasan ion $\mathrm{Ni}$ dan $\mathrm{Cr}$ kawat ortodontik stainless steel yang direndam dalam minuman berkarbonasi [Artikel Ilmiah Hasil Penelitian Mahasiswa]. Jember: Universitas Jember; 2014.

14. Schiff N, Dalard F, Lissac M, Morgon L, Grosgogeat B. Corrosion resistance of three orthodontic brackets: a comparative study of three fluoride mouthwashes. Eur J Orthod. 2005;27:541-9.

15. Schmalz G, Arenholt-Bindslev D. Biocompatibility of dental materials. Berlin: Springer-Verlag, 2009; p. 224-5.

16. Bonde MM, Fatimawali, Anindita PS. Uji pelepasan ion logam nikel $(\mathrm{Ni})$ dan kromium (Cr) kawat ortodontik stainless steel yang direndam dalam air kelapa. Pharmacon. 2016;5(4):40-5.

17. Almeida PDV, Gregio AMT, Lima, AAS, Azevedo LR. Saliva composition and function: a comprehensive review. $\mathrm{J}$ Contemp Dent Pract. 2005;9(3):58492.

18. Laksmitaputri P, Prahastuti N. Perbandingan antara pemakaian pasta gigi ortodontik dan pasta gigi herbal terhadap penurunan indeks plak pada pasien ortodontik cekat [Tesis]. Yogyakarta: Universitas Muhammadiyah; 2015. 